\title{
Nemo propheta in patria
}

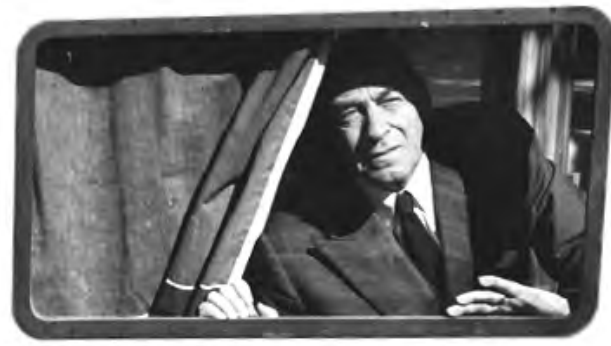

- NEMO PROPHETAIN PATRIA

"Nadie es profeta en su tierra" es la frase que rezaba bajo la ventana del paquebote diseñado por Aalto. Un barquito construido para cruzar el lago que le acercaba a su nuevo retiro en Muuratsalo.

Retomando una reflexión de Luis Fernández Galiano y retorciéndola hasta el absurdo me voy a permitir, en esta isla de insensatez en la que se ha convertido el editorial, establecer un paralelismo inverosímil y un tanto torticero entre España y algunas referencias nórdicas.

Galiano relaciona la frase con un cierto rencor de Aalto hacia sus paisanos por no haber digerido su marcha a EEUU durante las "guerras de invierno y de continuación" frente a los rusos en lugar de haber permanecido estoicamente en Finlandia defendiendo su tierra. La mirada entre lacónica y avinagrada de Aalto lo dice todo.

Finlandia había atravesado, sin Aalto en el frente, la peor de sus crisis, embarcada en el bando perdedor de la II Guerra Mundial. Después vino el protectorado vecino de una Rusia en recesión que dejó al hijo pródigo sin encargos. La calma chicha. La muerte de Aino le arrastró a la bebida. Sumergido entre el Koskenkorva y el bourbon durante tres años comenzó a ver la luz a través de una arquitecta 24 años más joven. Elsa Kaisa Mäkiniemi, Elissa para él.

Seguro que muchos arquitectos españoles ya se sienten identificados con alguno de estos pasajes tras la terrible crisis que les ha tocado sortear los últimos años. Que nos ha tocado vivir.

Es entonces cuando, casi sin trabajo, levanta una casita experimental junto a la joven arquitecta. Ladrillos, cerámicas y cubiertas inclinadas. Una casa patio. Un catálogo de soluciones agónicas, románticas, vernáculas, divertidas... El penúltimo estertor de un genio.

La arquitectura nórdica ha sido para España como un referente homeopático al que recurrir en tiempos de vacío existencial. La Escuela de Madrid, con todos sus maestros desaparecidos durante la guerra civil, puso el foco en Asplund, Lewerentz, el primer Aalto, Utzon o Jacobsen durante los años cincuenta, sesenta y setenta. Mientras que ahora, tras otro periodo oscuro, es la escuela mediterránea, por no reducirlo solo a la catalana, la que se ha apresurado a retomar el hilo más romántico y desenfadado de este Aalto tardío, pasando por Piétilä, con permiso de Miralles. Estas interpretaciones neo-neo vernáculas, matéricas o despojadas de capas, pero no de voluntad figurativa, han arrastrado, en cierto modo, al resto de España. Nos encontramos ahora con una suerte de superficies honestas a la par que fotogénicas. María González y Juanjo López de la Cruz se encargan de analizarlo de manera ortodoxa más adelante.

He tenido la oportunidad de formar parte del último jurado de la Bienal Española de Arquitectura y Urbanismo. Primera muestra post-crisis que recogía más de 300 obras de los últimos dos años. Con todos mis respetos a las obras presentadas he de reconocer una preocupante sobreexposición cerámica. Uno se pregunta cuánto de ello hay de sincero y cuánto se presenta al albur de esta nueva corriente.

Les dejo este plano de la vivienda experimental de Muuratsalo a modo de recordatorio, por si les resultara familiar ...

\section{Arturo Franco}


Sección. Dibujo: Museo Alvar Aalto

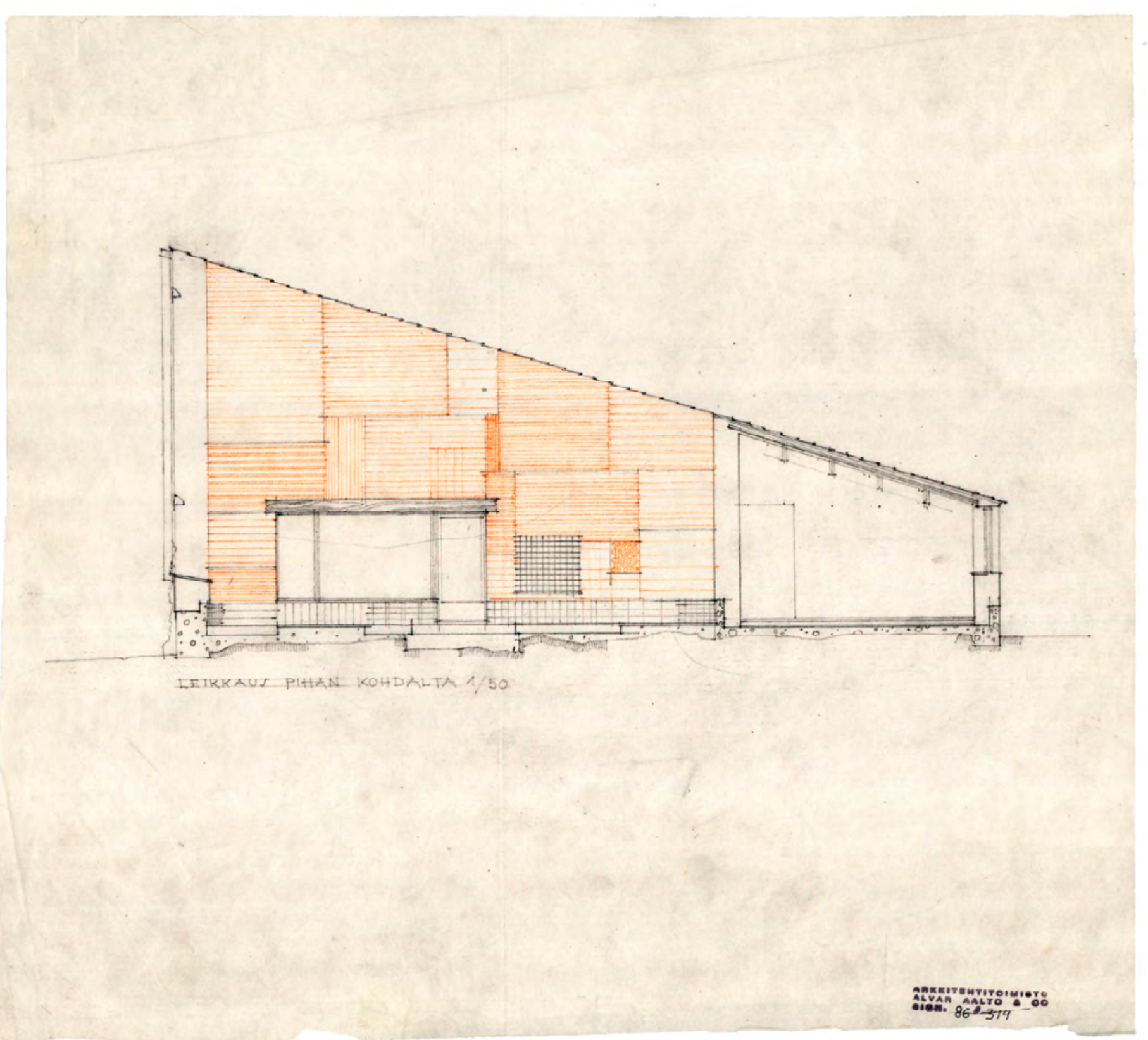

